\title{
A SUPERAÇÃO DA DICOTOMIA PÚBLICO X PRIVADO E A CONCEPCÃO SOLIDARISTA DE ACESSO À JUSTIÇA NO ENSINO DO DIREITO
}

\author{
THE OVERCOMING OF THE PUBLIC X PRIVATE DICOTOMY \\ AND THE SOLIDARIST CONCEPTION OF ACCESS TO JUSTICE \\ IN THE LEGAL TEACHING \\ Jorge Renato dos Reis ${ }^{1}$ \\ Aneline dos Santos Ziemann ${ }^{1}$
}

\section{Recebido em: 22/11/2017 Aceito em: 29/12/2017 jreis@unisc.br aneziemann@yahoo.com.br}

Resumo: O presente artigo teve como objetivo verificar o que se pode considerar como "acesso à justiça" nos termos atuais, considerando a superação da dicotomia público $\mathrm{x}$ privado, e como ocorre o ensino desta concepção nos cursos de Direito. Com este objetivo foi realizada a pesquisa bibliográfica na doutrina especializada no tema. Concluiu-se que há um distanciamento entre a formação que seria capaz de promover um acesso à justiça efetivo e a formação que é ofertada atualmente nos cursos de graduação em Direito. O excesso de legalismo dos cursos de Direito e o apego a percepções ultrapassadas, tais como a separação entre direito público e direito privado, é um dos fatores que contribui para que o Poder Judiciário encontre dificuldades para solucionar as demandas que a ele são levadas.

Palavras-chave: Dicotomia público x privado. Ensino Jurídico. Justiça. Solidarismo.

Abstract: This article aimed to verify what can be considered as "access to justice" in the current terms, considering the overcoming of the public $\mathrm{x}$ private dichotomy, and how the teaching of this conception occurs in Law courses. With this objective, a bibliographic research was carried out in the doctrine specialized in the theme. It was concluded that there is a gap between the training that would be able to promote access to effective justice and the training that is currently offered in undergraduate courses in Law. The excess of legalism in law courses and the attachment to outdated perceptions, such as the separation of public law and private law, is one of the factors that contributes to the difficulty of the Judiciary to solve the demands that are brought to it.

Keywords: Public x private dichotomy. Legal Teaching. Justice. Solidarism.

\section{INTRODUÇÃO}

Trabalhar com o novo tem sido um grande desafio para os Tribunais brasileiros. Mesmo após a mudança promovida pelo festejado "Novo Código de Processo Civil", unido a outras tentativas de desjudicialização de conflitos (como por exemplo a ampliação de possibilidades de solução extrajudiciais, como a usucapião extrajudicial, o divórcio consensual e o inventário extrajudicial) a verdade é que os Fóruns seguem recebendo mais demandas do que conseguem movimentar.

Esta percepção tão cotidiana aos operadores do Direito é traduzida em números pelos relatórios ${ }^{2}$ anuais realizados pelo Conselho Nacional de Justiça na busca pela avaliação da situação do Poder Judiciário brasileiro.

\footnotetext{
${ }^{1}$ Universidade de Santa Cruz do Sul - UNISC - Santa Cruz do Sul - Rio Grande do Sul - Brasil

${ }^{2}$ Neste sentido veja-se: Justiça em Números 2017: ano base-2016. Conselho Nacional de Justiça - Brasília: CNJ, 2017.
} 
Diante desta realidade, inevitável ao operador do Direito a reflexão em torno das possíveis causas e soluções para este problema. Porque não se consegue estabelecer uma cultura de resolução de conflitos de forma independente da prestação Estatal na figura do Poder Judiciário? Por quais razões, apesar dos esforços legislativos e da existência de alternativas o Poder Judiciário continua sendo percebido como o grande elemento de pacificação social? Se é ensinado nos bancos acadêmicos que o Poder Judiciário é o último recurso para a solução de controvérsias porque o número de demandas propostas cresce ano após ano?

A reflexão caminha inevitavelmente para o fato de que, por mais que a democratização do ensino possibilitou que inúmeras pessoas tivessem acesso aos cursos de Direito, em termos de realidade social o que se tem não é uma maior facilidade em solucionar lides: pelo contrário, o Poder Judiciário nunca esteve tão abarrotado. Portanto, o que os cursos de Direito têm oferecido para a sociedade: "pacificadores" de conflitos ou "criadores" de conflitos? Nestes termos, questiona-se também a cômoda postura dos atores privados que se sentem alheios à responsabilidade de promover a justiça: este é mesmo um papel a ser desempenhado unicamente pelo Estado através de seus agentes?

É em torno de tais provocações que serão desenvolvidas as breves reflexões que seguem.

\section{A SUPERAÇÃO DA GRANDE DICOTOMIA PÚBLICO X PRIVADO NO DIREITO BRASILEIRO E A NOVA CONCEPÇÃO DE ACESSO À JUSTIÇA PÓS CONSTITUIÇÃO FEDERAL DE 1988}

Um dos grandes "mitos" do Direito e que insiste em sobreviver ao passar do tempo é o da chamada "grande dicotomia" entre o Direito Público e o Direito Privado. Mito porque, conforme se verá, esta separação não pode ser percebida como absoluta. A respeito desta dicotomia destacam-se as lições de Norberto Bobbio³.

Toda a reflexão humana a respeito da vida em sociedade nasce da construção de "grandes dicotomias". Desde a dicotomia entre estado de inocência ou de corrupção, passando pela dicotomia estado de natureza $\mathrm{x}$ sociedade civil e chegando à dicotomia despostismo $\mathrm{x}$ liberdade $\mathrm{e}$ posteriormente à dicotomia marxista sociedade de classes $\mathrm{x}$ sociedade sem classes. $\mathrm{O}$ refletir sobre as dicotomias foi assumido pela Sociologia a partir do advento da sociedade industrial. (BOBBIO, 2007)

Voltando os olhos especificamente para o Direito, a separação que de forma mais contundente revela os moldes de uma "grande dicotomia" é a separação entre direito privado e direito público. Esta distinção serve "[...] para dividir em duas subclasses, reciprocamente excludentes e exaustivas, o universo do direito." (BOBBIO, 2007, p. 143) Entre outras grandes dicotomias que permeiam o universo jurídico, convém destacar as características desta que foi eleita para a presente pesquisa.

\footnotetext{
${ }^{3}$ Neste sentido, ver: BOBBIO, Norberto. Da estrutura à função: novos estudos de teoria do direito. Tradução: Daniela Beccaccia Versiani; revisão técnica de Orlando Seixas Bechara, Renata Nagamine. Barureri, SP: Manole, 2007.
}

Revista do Direito [ISSN 1982-9957]. Santa Cruz do Sul, v. 3, n. 53, p. 104-120, set./dez. 2017. https://online.unisc.br/seer/index.php/direito/index 
A distinção dos universos do direito em público e privado é uma distinção total. Isto porque, independente do critério sob qual se funde tal separação, não há qualquer ente jurídico que não faça parte de uma ou de outra destas categorias. Isso quer dizer que, pode haver ente que pertença a ambas, mas não haverá aquele que não pertença a nenhuma. Esta dicotomia é, também, principal já que tende a absorver outras dicotomias. Dentro desta grande categoria existem outras categorias secundárias, como por exemplo, a dicotomia justiça comutativa x justiça distributiva. (BOBBIO, 2007)

Observada sob o viés da história do direito, o direito público e o direito privado surgem não como partes do sistema jurídico, mas como momentos distintos da evolução deste sistema. Isso é o que se percebe em falas como "tendência à privatização" ou de uma 'tendência à publicização". Assim é que na medida em que a oposição Estado x sociedade civil se acentuava e a sociedade civil ganhava proeminência a partir da afirmação da idéia de diminuição do Estado, naturalizava-se um momento privatista do direito. Já no início do século XX e a partir do declínio das instituições clássicas do direito privado, ganhava força a publicização do direito, fortemente reconhecida como uma característica do direito contemporâneo. (BOBBIO, 2007)

Não seria exagero reforçar que as esferas pública e privada refletem imagens diferentes do direito. Para os privatistas o direito se confundiria com a figura do árbitro chamado a solucionar conflitos, já para os publicistas a figura que melhor representaria o direito seria a do comandante que unifica esforços em torno do objetivo comum. (BOBBIO, 2007) Em síntese, é preciso perceber que:

O contraste entre estas duas imagens do direito explica por que a busca por um critério de distinção entre direito privado e direito público é sempre tão difícil a ponto de parecer uma tentativa desesperada. Não nos apercebemos de que, nessa distinção, estão em choque não duas espécies de um único gênero, mas sim, dois modos diversos de conceber o mesmo objeto, ou se quisermos, dois pontos de vista diferentes. (BOBBIO, 2007, p. 152)

Ou seja, respeitados os profundos esforços no sentido de se alcançar uma clara distinção entre direito público e direito privado, percebe-se que esta distinção se mostra tão complexa justamente porque na verdade se tratam apenas de modos diverso de se observar o mesmo objeto: 0 direito.

Contemporaneamente, esta concepção de que a separação do direito público e do direito privado em esferas diferentes não passa de uma forma de equivocada de observar o direito que, em verdade é um só, já se encontra consolidada na literatura jurídica mais atual. É justamente em razão da superação deste paradigma que hoje o Direito Civil, baluarte maior do Direito Privado, é analisando sob o viés constitucional, eixo fundamental do Direito Público, de acordo com o chamado "Direito Civil - Constitucional".

No Brasil a crescente influência do Estado social na preservação dos interesses coletivos, a maior ingerência do Estado na economia, a sua consequente limitação da autonomia privada bem 
como o deslocamento da Constituição do papel de "mera carta política" para o eixo fundamental do ordenamento jurídico, deram origem à chamada "constitucionalização do direito". (RODRIGUES,2014)

A constitucionalização do direito privado, e notadamente do direito civil, impôs a superação do modelo patrimonialista e individualista sob o qual o direito civil de raízes oitocentistas foi construído. (RODRIGUES, 2014) Impôs, inclusive, a superação da seguinte e já deposta concepção:

É a concepção, já ultrapassada, de que o direito civil cuida e resolve as questões que envolvem interesses individuais e ao direito constitucional, restaria as questões relativas à organização do Estado. Seria o dualismo direito público versus direito privado. O Estado cuidando do interesse coletivo, as pessoas de seus interesses. Cada um em searas diferentes, em círculos com quase nenhuma intersecção. (RODRIGUES, 2014, p. 554)

Dito de outra forma, se mostra ultrapassado acreditar que somente o Estado é responsável pela salvaguarda dos interesses coletivos.

A constitucionalização do direito privado é a percepção de que o direito privado somente pode ser concebido, lido e interpretado sob a ótica dos princípios e regras constitucionais. (REIS, 2003, p. 786-787) É esta percepção de que a Constituição é a lei maior, e de que, portanto, não há ramo algum do Direito que a ela não esteja inexoravelmente submetido que desafia as estremas entre direito público e direito privado e até mesmo entre o Estado e a sociedade civil. (SARMENTO, 2007)

Assim é que se impõe a leitura do ordenamento jurídico enquanto complexo unificado no qual os princípios constitucionais atuam enquanto guias e centros das múltiplas fontes do Direito. Portanto, torna-se impossível perceber o ordenamento jurídico pátrio enquanto um sistema fragmentado, composto de ramos autônomos e incomunicáveis. (PERLINGIERI, 2008)

As codificações liberais e o seu universo de segurança foram reflexo do primado do direito privado sobre o direito público. O ideário inaugurado pelo Welfare State e o advento do constitucionalismo social alterou esta lógica. As constituições do pós-guerra se voltaram à salvaguarda da igualdade substancial, ainda que para isso tenham que interferir, em alguma medida, no âmbito da liberdade econômica. No direito privado este ideário é internalizado pela limitação da vontade dos particulares e pela realização do princípio da solidariedade social. Abandonou-se, assim, a ética individualista, abrindo-se espaço para a ética solidarista, restringindo-se a autonomia da vontade $^{4}$ em favor da tutela da dignidade da pessoa humana. (FACHINI NETO, 2010)

\footnotetext{
${ }^{4}$ Neste sentido: "[...] o excesso de individualismo que transformou o homem contemporâneo é fruto de uma não recepção das condutas solidárias [...] provocando uma padronização nas ações do indivíduo e uma ausência de trejeitos para com a necessidade de visualizar a coletividade." (REIS; FONTANA, 2010, p. 3328 3329)
}

Revista do Direito [ISSN 1982-9957]. Santa Cruz do Sul, v. 3, n. 53, p. 104-120, set./dez. 2017. https://online.unisc.br/seer/index.php/direito/index 
O constitucionalismo contemporâneo tem como eixo, portanto, a dignidade da pessoa humana e também a solidariedade social, estendendo sua principiologia para a esfera privada, de maneira que o direito privado necessariamente deverá ser exercido de forma a privilegiar o bem-estar coletivo. (CARDOSO, 2013)

E este ponto é fulcral ao estudo que aqui se desenvolve. Ora, se o direito privado contemporâneo superou a grande dicotomia público x privado e já não se volta apenas aos interesses individuais, porque razão segue sendo uma tarefa atribuída unicamente ao Estado (à esfera pública) a resposta a demandas sociais? Não há também para os particulares, dentro da percepção de um direito privado constitucionalizado, o dever de zelar pelo bem-comum? No sentido de aprofundar estas reflexões é que segue o breve referencial teórico aqui exposto.

\title{
3. OS MEIOS DE SOLUÇÃo DE CONFLITOS A PARTIR DA SUPERAÇÃO DA DICOTOMIA PÚBLICO X PRIVADO E A CONCEPÇÃO CONTEMPORÂNEA DE ACESSO À JUSTIÇA
}

Contemporaneamente, considerando inclusive a superação da grande dicotomia anteriormente mencionada, é importante que se alcance uma concepção de acesso à justiça que considere as particularidades do momento presente.

A complexidade que o tema "justiça" encerra pode ser refletida nas palavras de Amartya Sen (2011, p. 436):

\begin{abstract}
A justiça é uma ideia de imensa importância que moveu as pessoas no passado e continuará a movê-las no futuro. $E$ a argumentação racional e o exame crítico podem realmente oferecer um grande auxílio para ampliar o alcance e refinar o conteúdo desse conceito fundamental. No entanto, seria um erro esperar que todos os problemas decisórios com os quais a ideia de justiça tenha alguma relação concebível fossem resolvidos por meio do exame arrazoado. E também, como dissemos antes, seria um erro supor que, já que não é possível resolver todas as disputas através do exame crítico, então não teríamos bases sólidas suficientes para utilizar a ideia de justiça nos casos em que o exame racional leva a um juízo conclusivo. Vamos até onde razoavelmente podemos ir.
\end{abstract}

Razoavelmente, portanto, busca-se abordar esta ideia sob o ponto de vista da ciência do direito enquanto elemento substancial de toda a movimentação judiciária.

Buscando na literatura jurídica clássica, chega-se a Cappelletti e Garth (2002) que desenvolvem uma digressão histórica a respeito do tema. Nos Estados liberais dos séculos XVIII e XIV, a resolução de litígios civis refletia a filosofia individualista da época. Assim é que estar sob a proteção judicial significava apenas possuir formalmente o direito de propor ou responder a uma ação. Estudava-se o acesso à justiça de maneira alheia aos reais problemas sociais. Na medida em que o tempo avançou e que as reformas do welfare state procuraram assegurar um conteúdo mais amplo de direitos foi que o efetivo acesso à justiça passou a ser objeto de atenção. (CAPPELLETTI; GARTH, 2002) 
Houve, desde então um progressivo reconhecimento de que o acesso à justiça é tema de destacada relevância, ao menos para aqueles sistemas jurídicos que cuidam de garantir e não apenas de proclamar os direitos dos seus cidadãos. Este é o enfoque, como não poderia deixar de ser, do processo civil contemporâneo. (CAPPELLETTI; GARTH, 2002) Entre os processualistas contemporâneos, o tema tem ocupado posição de destaque, fato perceptível diante das últimas reformas processuais.

Outro fator que impõe uma nova reflexão a respeito do acesso à justiça é a violência que frutifica da perpetuação das desigualdades e do aumento da complexidade social. Nas palavras de Sério Adorno (2002, p. 88):

\begin{abstract}
A desigualdade de direitos e de acesso à justiça agravou-se na proporção mesma em que a sociedade se tornou mais densa e mais complexa. Os conflitos sociais tornaram-se mais acentuados. Neste contexto, a sociedade brasileira vem conhecendo crescimento das taxas de violência nas suas mais distintas modalidades: crime comum, violência fatal conectada com o crime organizado, graves violações de direitos humanos, explosão de conflitos nas relações pessoais e intersubjetivas.
\end{abstract}

O acesso à justiça é concebido atualmente não apenas como uma simples atividade de aplicação do direito de acordo com a clássica concepção de Montesquieu. Hoje a jurisdição é percebida como uma atividade que possui função social, dentro de uma perspectiva de Estado intervencionista. (RODRIGUES,2000) Dentro da amplitude de significados da expressão "acesso à justiça" importa que se tenha em mente que esta expressão não se limita ao acesso ao Poder Judiciário ou ao direito estatal como um todo. Portanto, deve se tomar cuidado para não reduzir o acesso à justiça à mecanismos processuais e sua efetividade. Trata-se, isto sim, de possibilitar aos cidadãos o acesso à uma ordem jurídica justa, não apenas do acesso a uma Justiça enquanto instituição do Estado. (RODRIGUES, 2000) Necessário, portanto, ampliar o foco de visão para que não se perceba o tema do acesso à justiça de maneira restrita a apenas uma de suas faces, qual seja, a dos mecanismos processuais e estatais.

Além disso, ao se falar em "acesso à justiça" é preciso lembrar que se está tratando de um direito humano e que, como tal, requer ampla proteção e promoção tanto por parte do Estado quanto por parte da sociedade. Esta proteção/promoção pode se dar tanto por meio de condutas negativas, ou seja, mediante a abstenção de atos que atentem contra o acesso à justiça quanto por meio de condutas positivas, quais sejam, aquelas que promovem este acesso. (RESCHKE, BAEZ, 2017)

Ao mesmo tempo em que não se deve restringir o acesso à justiça a uma concepção ligada exclusivamente ao acesso aos instrumentos processuais capazes de efetivar direitos, também não se deve afastar o acesso à justiça do acesso ao Judiciário, sob pena de tornar intangível o exercício da cidadania. Há, no entanto, conforme explica Horácio Wanderlei Rodrigues (sem grifo no original, 2000, p. 7):

Há aqueles conflitos que podem e devem ser solucionados através de instrumentos paraestatais ou privados. Mas é fundamental perceber-se que o Estado, sem a jurisdição, seria uma instituição política desprovida de um 
instrumento legítimo, através do qual possa exercitar seu poder, em última instância, na busca da pacificação da sociedade. Sempre que um direito não for respeitado espontaneamente, não há como fazê-lo legitimamente senão através do processo.

Há, ainda outra ressalva a ser feita. Em uma sociedade complexa como a contemporânea, o sistema educacional possui destacado papel na questão do acesso à justiça. O conhecimento a respeito dos direitos fundamentais sociais e individuais e dos instrumentos pertinentes à sua efetivação, bem como a educação para a cidadania enquanto busca por direitos é imprescindível para o efetivo acesso à justiça. (RODRIGUES, 2000)

Também é necessário pontuar que o acesso à justiça se relaciona intimamente com a qualidade dos profissionais que possuem capacidade postulatória. A efetividade do acesso à justiça depende intimamente da qualidade dos profissionais em atuação. No entanto, predomina a baixa qualidade do ensino do Direito no país, no sentido de ser um ensino eminentemente legalista e reprodutor do status quo, o que reflete em uma má formação dos bacharéis. $O$ aumento de cursos de Direito dos últimos anos não foi acompanhado de uma estrutura e corpo docente adequados. Além disso, a dinâmica da sociedade, em constante movimento, exige do bacharel em Direito (e notadamente do advogado), uma visão ampla, capaz de englobar as mudanças culturais, políticas e econômicas, possibilitando ao profissional uma assessoria completa e competente para o seu cliente. Também, as exigências práticas dos profissionais do Direito se modificaram, sem que os cursos acompanhassem essas mudanças.( RODRIGUES, 2000, p. 7)

Enquanto tutela jurisdicional, a efetividade do acesso à justiça requer a observância de alguns requisitos, tal como o patrocínio por um advogado, ou seja, a defesa técnica enquanto elemento da ampla defesa, constitucionalmente garantida ${ }^{5}$. (GRECO, 2015) Portanto, é, ademais, conteúdo da ampla defesa o patrocínio de demandas judiciais ou o atendimento extrajudicial por profissional competente para tanto.

Em muitos casos, a solução prevista em lei não se revelará a mais adequada para o caso concreto, de forma que as partes podem procurar outros meios, que não o processo judicial, para solucionar suas divergências. Cabe ao direito processual prestigiar tais práticas, desde que, certamente, elas sejam escolhidas pelas partes. Em algumas sociedades, a exemplo da norteamericana, a expansão de meios alternativos de solução de conflitos aconteceu paulatinamente. São as chamadas "ADRs" (alternative dispute resolution ${ }^{6}$ ) que pouco a pouco foram sendo recepcionados legalmente, a exemplo da mediação, da arbitragem, do rent a judge, do ombudsmen, entre outros. (GRECO, 2015)

O Brasil, inicialmente, implementou iniciativas tímidas no sentido da adoção dos meios alternativos, a exemplo da Justiça do Trabalho que desde a sua instituição (1946) tem um viés predominantemente conciliatório. No ano de 1996 o Brasil adotou a Lei №. 9.307/96, a Lei de

\footnotetext{
5 "Art. 5․

$[\ldots]$

LV - aos litigantes, em processo judicial ou administrativo, e aos acusados em geral são assegurados o contraditório e ampla defesa, com os meios e recursos a ela inerentes;

[...]" (BRASIL,1988)

${ }^{6}$ Resoluções alternativas de conflitos, em tradução livre.
} 
Arbitragem avançando na consolidação dos meios alternativos. Em 2004, a partir da criação do Conselho Nacional de Justiça, este passou a fomentar a conciliação e a mediação mediante a Resolução no. 125/2010. O governo federal também vem demonstrando esforços neste sentido, no II Pacto Republicano de $2009^{7}$ foi incluído como objetivo o estímulo à solução de conflitos por meios autocompositivos, e no ano de 2012 o Ministério da Justiça fundou a Escola Nacional de Mediação e Conciliação. (GRECO, 2015) Tais são, portanto, medidas que demonstram o caminho que o direito processual contemporâneo vem trilhando.

O Novo Código de Processo Civil também privilegia a mediação e a conciliação regulando a forma como tais métodos serão utilizados no decorrer do processo. O critério de diferenciação que se extrai do Novo Código de Processo Civil, com relação à mediação e à conciliação seria a existência de vínculo ou não entre as partes. Destaque-se que de acordo com a lógica proposta pelo Novo Código, há que se encorajar também, a mediação extrajudicial, bem como a pré-processual, especialmente nas relações entre familiares e nas demais relações jurídicas duradouras, de maneira que se possibilite a tais relações, o acesso a soluções rápidas e eficientes. (GRECO, 2015)

$\mathrm{O}$ acesso à justiça nos termos em que aqui se propõe, encontra ainda outro desafio além dos já mencionados, qual seja, a quase inexistência de instituições que se encarreguem de uma prestação jurídica preventiva e extrajudicial. O processo administrativo não é percebido enquanto meio processual em razão de não se tratar de meio judicial. Ainda assim, o processo administrativo também exige o acompanhamento de um profissional preparado para buscar, ainda que extrajudicialmente a tutela efetiva dos direitos do seu cliente. (RODRIGUES, 2000, p. 7)

Questiona-se, portanto, diante do quadro exposto, porque esta preparação para a atuação administrativa e extrajudicial não é oferecida, em regra, pelos cursos de graduação em Direito? Contemporaneamente o acesso ao direito depende de um ensino jurídico que torne possível aos futuros operadores do Direito, o contato com os mecanismos não litigiosos e não necessariamente judiciais, de solução de conflitos. Porém, esta não parece ser a realidade oferecida pelos cursos de Direito na forma como são estruturados atualmente. É sobre a análise dos cursos de graduação em Direito que o próximo tópico irá refletir.

\section{OS CURSOS DE GRADUAÇÃO EM DIREITO NO BRASIL E A EVOLUÇÃO PEDAGÓGICO- JURÍDICA DOS SEUS PARADIGMAS FUNDANTES}

\footnotetext{
7 "Firmar o presente PACTO REPUBLICANO DE ESTADO POR UM SISTEMA DE JUSTIÇA MAIS ACESSÍVEL, ÁGIL E EFETIVO, com os seguintes objetivos:

I - acesso universal à Justiça, especialmente dos mais necessitados;

II - aprimoramento da prestação jurisdicional, mormente pela efetividade do princípio constitucional da razoável duração do processo e pela prevenção de conflitos;

III - aperfeiçoamento e fortalecimento das instituições de Estado para uma maior efetividade do sistema penal no combate à violência e criminalidade, por meio de políticas de segurança pública combinadas com ações sociais e proteção à dignidade da pessoa humana.

Para a consecução dos objetivos estabelecidos neste Pacto, assumem os seguintes compromissos, sem prejuízo das respectivas competências constitucionais relativamente à iniciativa e à tramitação das proposições legislativas:

[...] d) fortalecer a mediação e a conciliação, estimulando a resolução de conflitos por meios autocompositivos, voltados à maior pacificação social e menor judicialização; [...]" (BRASIL, 2009)
} 
Conforme se depreende de todo o acima exposto, há toda uma complexidade no momento atual do Direito: demandas sociais em escala crescente, o aumento exponencial da litigiosidade, um Poder Judiciário que não consegue responder satisfatoriamente a todas estas demandas e de tudo isso surge, inevitavelmente, a dúvida a respeito da formação jurídica dos atuais operadores do Direito. Necessário, portanto, realizar uma rápida análise dos cursos de Direito no Brasil, afim de identificar seus contornos e sua realidade atual.

Os cursos de Direito criados no Brasil do século XIX o propósito principal de fornecer ao Império recursos humanos que pudesse ocupar as carreiras burocráticas. Assim, é possível perceber que o jurista brasileiro nasceu com funções intimamente ligadas ao Estado, tanto enquanto funcionário deste, como enquanto mecanismo de desenvolvimento das capacidades do Estado nacional. Este desenho de bacharel era claramente o do burocrata oriundo de uma sociedade escravista e clientelista, que promovia a sua ascensão profissional por meio de indicações e alianças políticas junto aos detentores do poder em qualquer das esferas. (LOPES, 2011)

O debate em torno da qualidade do ensino e das atribuições que o operador do Direito deve desempenhar surgiu simultaneamente à criação dos cursos de Direito no Brasil. De fato, a educação jurídica do século XIX se voltava basicamente à formação de bacharéis em seu aspecto formal, e não à uma educação jurídica com viés pedagógico. (BENTO; MACHADO, 2013) Contemporaneamente, além de outros tantos questionamentos, como por exemplo, o da formação excessivamente legalista, questiona-se também a respeito de uma cultura do litígio perpetuada nos bancos acadêmicos.

Conforme explica Rodrigues (1993, p. 21) "o ensino jurídico, fazendo parte do mundo do Direito, reflete tanto a crise deste como a do sistema sócio-político-econômico em sua totali- dade. A sua estrutura e as várias funções por ele desempenhadas começam também a ser questionadas." É, portanto dentro do refletir do ensino jurídico que se reflete, também, a respeito da própria função do Direito ${ }^{8}$.

Conforme anteriormente mencionado, o Poder Judiciário vem enfrentando uma crise que, embora não tenha como causa unicamente o volume de ações, tem neste fato uma de suas razões. O que ocorre é que o grande volume de ações torna extremamente difícil uma prestação jurisdicional efetiva e, consequentemente, o próprio acesso à justiça. Uma das maneiras pelas quais se pode buscar solucionar (ou ao menos amenizar) este problema é superando a cultura do litígio mediante a utilização dos meios não litigiosos de solução de conflitos. Porém, para que tais meios sejam efetivamente apropriados pela cultura jurídica é necessário que a formação dos bacharéis em Direito caminhe neste sentido.O que se observa é que apesar de existir a possibilidade jurídica de submissão de litígios à meios como, por exemplo, a arbitragem, esta opção dificilmente ocorre justamente em virtude da cultura predominante de que o acesso ao Poder Judiciário é a única forma de se solucionar um conflito. (COUTO; MEYER-PFLUG, 2013)

Neste ponto é possível conectar a temática aqui desenvolvida com a abordagem de Edgar Morin para quem a missão do ensino não se resume à mera transmissão do saber, mas engloba a

\footnotetext{
${ }^{8} \mathrm{O}$ tópico seguinte abordará com maior propriedade a questão da estrutura e da função do Direito.
} 
transmissão de toda uma cultura que ajude a enfrentar a vida e que ao mesmo tempo favoreça a liberdade de pensamento. (MORIN, 2003)

Necessário pontuar também que, não obstante as medidas que vem sendo tomadas no sentido de substituir a cultura do litígio pela cultura da solução consensual de conflitos, a exemplo do já mencionado conteúdo do Novo Código de Processo Civil, não se pode esquecer a responsabilidade do ensino jurídico nesta mudança de cultura. Porém, a atual grade curricular dos cursos de Direito brasileiros revela uma tendência oposta à necessária. Pesquisa realizada pelo INEP em 2008, por exemplo, demonstrou que das trinta maiores Instituições de Ensino do País, 53,8\% delas não contempla disciplinas voltadas para a mediação, conciliação e arbitragem. (COUTO; MEYER-PFLUG, 2013) Se ao longo de sua formação, os bacharéis não são apresentados a estes meios, como incorporarão esta lógica à sua cultura profissional?

O mercado de trabalho demonstra claramente a disfunção que existe entre o produto final do ensino do Direito e as necessidades postas pela sociedade contemporânea. Entender que o mercado de trabalho está saturado é a prova desta disfunção. O que existe, em verdade, é um novo mercado sem profissionais capazes de nele operar. O judicialismo é resultado disto: a crença de que o jurista é aquele profissional que resolverá em juízo os litígios que a ele são levados e consequentemente uma formação profissional que se restringe à manipulação teórica e formal do processo. Não se traz à tona o fato de que a maioria dos conflitos podem ser, primeiramente, evitados e em segundo caso, resolvidos extrajudicialmente. (RODRIGUES, 1993, p. 24) Portanto:

Há a necessidade, nesse sentido, de redirecioná-lo para a preparação de profissionais em função de dois novos horizontes: a) atuarem na advocacia preventiva, principalmente nas denominadas assessorias e consultorias jurídicas, e b) trabalharem com a advocacia conciliatória, buscando a efetivação de acordos sem a necessidade de levar conflitos ao judiciário.

Existem propostas de reformas curriculares das mais variadas, indo dede o extremo humanismo até o seu oposto, o radical tecnicismo. A problemática da interdisciplinaridade é, no entanto, uma das mais recorrentes preocupações daqueles que se dedicam ao tema do ensino jurídico. Isso porque os currículos jurídicos se mostram muito resistentes ao ensino interdisciplinar. $E$ é justamente quando se percebe a necessidade da reflexão multidisciplinar capaz de oferecer uma perspectiva crítica dos institutos jurídicos e de suas funções. É preciso que se discuta a função social do jurista. (RODRIGUES, 1993)

Aqui chega-se ao problema da chamada "hiperespecialização alienante", ou seja, de uma especialização tão profunda em determinada área que acabe por impedir a visão do todo. (RODRIGUES, 1993)

Em termos de ensino, existe nas universidades uma incongruência que vem se aprofundando e se agravando com o passar do tempo, qual seja, a problemática dos saberes fragmentados (anteriormente mencionado), separados entre disciplinas e aos quais são opostos realidades polidisciplinares, multidisciplinares e transversais. A hiperespecialização, aquela especialização profundamente fechada em si mesma, impede a percepção do todo, do global e foca seus agir apenas em uma parcela do todo. A questão é que os problemas essenciais jamais são fragmentáveis 
e mesmo os problemas particulares somente podem ser corretamente analisados diante do seu contexto (MORIN, 2003)

Assim é que se retoma a problemática anteriormente mencionada, a respeito da crise do acesso à justiça, do Poder Judiciário, da litigiosidade e do ensino jurídico fragmentado e legalista. Trata-se, obviamente, de um problema complexo, assim como todos problemas a serem enfrentados pelo jurista serão. Neste sentido, convém alertar:

Efetivamente, a inteligência que só sabe separar fragmenta o complexo do mundo em pedaços separados, fraciona os problemas, unidimensionaliza o multidimensional. Atrofia as possibilidades de compreensão e de reflexão, eliminando assim as oportunidades de um julgamento corretivo ou de uma visão a longo prazo. Sua insuficiência para tratar nossos problemas mais graves constitui um dos mais graves problemas que enfrentamos. (MORIN, 2003, p. 14)

Necessário, portanto, relembrar que o conhecimento pertinente é aquele que possui a capacidade de atuar em seu contexto, e que a tendência a uma extrema compartimentação dos saberes pode acarretar a dificuldade em articulá-los. Além disso, a capacidade de contextualização e integração é fundamental para a mente humana, de modo que esta capacidade deve ser desenvolvida e não estagnada. (MORIN, 2003)

Ainda neste sentido, mencione-se que, entre os tantos movimentos que buscam respostas para o problema do atual estágio do ensino jurídico, encontra-se a Associação Crítica do Direito, movimento de professores, juristas e pesquisadores, que desde 1978 busca romper com a ideologia dominante nos cursos de Direito. Seus membros defendem uma análise histórica do Direito, questionam as tradicionais separações entre disciplinas jurídicas e políticas e criticam o ensino jurídico alheio à análise das reais funções do Estado e do Direito. Este movimento, além disso, questiona a distinção entre o direito público e o direito privado por entender que tais distinções são arbitrárias e prejudicam a pesquisa científica. (RODRIGUES, 1993)

A dificuldade de contextualização mencionada reflete, inclusive, na esfera cívica. A falta de uma percepção global dilui o senso se responsabilidade e de solidariedade, já que cada pessoa entende ser responsável unicamente pela sua tarefa. Rompe-se, assim, o elo orgânico com os demais componentes do corpo social. A reforma do pensamento, portanto, é que possibilitará o emprego da inteligência na busca por respostas a problemas complexos. Trata-se de uma reforma que busca uma nova forma de organizar o conhecimento. (MORIN, 2003) Em síntese: "uma cabeça bem-feita é uma cabeça apta a organizar os conhecimentos e, com isso, evitar sua acumulação estéril." (MORIN, 2003, p. 24) E é neste sentido, o da formação de uma "cabeça bem-feita" e não de uma "cabeça bem cheia" que o curso de Direito deve caminhar.

Portanto, a superação da dicotomia público $\mathrm{x}$ privado e da visão estanque de que cabe exclusivamente ao Estado solucionar litígios, somente pode ocorrer através da percepção do Direito enquanto complexo interdisciplinar. O último tópico deste breve referencial teórico segue no sentido de abrir caminhos para uma proposta de reforma da formação jurídica dos bacharéis em Direito. 


\section{O ACESSO A JUSTIÇA E A SUA CONCEPÇÃO CONTEMPORÂNEA NO ESTADO CONSTITUCIONAL SOLIDARISTA BRASILEIRO: A INAFASTABILIDADE DA FORMAÇÃO JURÍDICO-SOLIDÁRIA}

Conforme se buscou demonstrar desde o início deste ensaio teórico, há todo um complexo de problemas envolvendo a questão do acesso à justiça no Brasil na atualidade. Este problema se insere tanto dentro no contexto do Poder Judiciário brasileiro, ou seja, no contexto da política pública judiciária brasileira ${ }^{9}$ quanto no contexto da política pública de ensino superior, especificamente no que tange ao ensino jurídico ${ }^{10}$. Inicialmente, portanto, convém retomar a percepção de política pública.

A expressão "política pública", de acordo com Schmidt (2016, p. 1) pode ser entendida como:

[...] um conjunto de decisões e ações desencadeadas por órgãos públicos e entes da sociedade, dotadas de coerência intencional, que, sob coordenação estatal, visam a enfrentar um problema político. Toda política pública é uma tentativa de intervenção na realidade social, seja de controle ou de mudança.

Portanto, de acordo com as incursões acima realizadas, percebe-se que no âmbito do Poder Judiciário vem havendo uma série de esforços no sentido de se buscar uma melhor adaptação da política pública judiciária à realidade subjacente. Com relação ao ensino jurídico, percebe-se que há a necessidade de que ocorra a adaptação da formação oferecida ao futuro jurista para que este seja capaz de atuar conforme as necessidades que o mercado de trabalho do Direito exige atualmente.

Se a maioria dos litígios que chegam ao judiciários estão relacionados à área do direito privado/civil, isso significa que o ensino do direito ainda não adotou a ótica do direito civil constitucionalizado e, consequentemente, a visão de que o acesso à justiça deve ser promovido também pelos particulares. Isto no sentido de que não cabe apenas ao Poder Judiciário a busca pela pacificação social: aqueles que contratam, por exemplo, devem contratar de forma a evitar a ocorrência de litígios, e no caso de ocorrer o desentendimento, este deve ser solucionado extrajudicialmente, pois é dever de todos e não exclusivamente do Estado a preservação do bemcomum. Questiona-se, portanto, se a função do Direito está sendo perseguida.

O ordenamento jurídico é dotado não apenas de estrutura, mas também de funções próprias. Ou seja, não se resume a uma estrutura normativa, mas, antes, trata-se de um complexo com finalidades próprias a serem alcançadas. O Direito, portanto, possui uma função promocional. Pode, assim, tanto reprimir comportamentos indesejados, quanto se utilizar de ferramentas que premiam comportamentos desejados. (BOBBIO, 2007) Se no momento em que as partes que criaram um conflito conseguem o solucionar, sem ter que, para isso, recorrer a um longo e custoso processo, elas

\footnotetext{
${ }^{9}$ Neste sentido: WATANABE, Kazuo. Política Pública do Poder Judiciário Nacional para Tratamento Adequado dos Conflitos de Interesses. Disponível em: <http://www.tjsp.jus.br/Download/Conciliacao/Nucleo/ParecerDesKazuoWatanabe.pdf>. Acesso em: 21.10.2017.

${ }^{10}$ Neste sentido: PORTAL MEC. Resolução CNE/CES n 9, de 29 de setembro de 2004. Institui as Diretrizes Curriculares Nacionais do Curso de Graduação em Direito e dá outras providências. Disponível em: <http://portal.mec.gov.br/cne/arquivos/pdf/rces09_04.pdf>. Acesso em: 19.08.2017.
} 
acabam sendo premiadas pelo alcance da celeridade e do efetivo acesso à justiça, seria possível vislumbrar nesta situação a realização da função promocional do Direito? Acredita-se que sim.

Além disso, já no primeiro tópico deste referencial foi realizada a abordagem a respeito da constitucionalização ${ }^{11}$ do direito privado, fazendo-se uma rápida menção ao abandono da lógica individualista no direito privado brasileiro e consequente adoção de uma postura solidária, promovida pela Constituição Federal de 1988. Neste momento, importa aprofundar este aspecto.

O Estado democrático contemporâneo se caracteriza inafastavelmente por: estar comprometido com a sua função social de alcance da justiça social; possuir um caráter intervencionista (pressuposto essencial para o alcance de seu objetivo principal) e estruturar uma ordem jurídica que respeita a liberdade e igualdade em sentido material. Em outras palavras, trata-se de um Estado construído sob o suporte da solidariedade. (RODRIGUES, 2008)

A perspectiva solidária que se persegue enquanto novo paradigma do direito privado se constrói no sentido de que os institutos jurídicos sejam direcionados às suas funções originais: possibilitar a vida em sociedade de maneira digna, manter a paz social, alcançar o ideal de justiça e a liberdade. Nesta concepção, é pelo direito privado que se desenvolve a noção de cooperação e de responsabilidade social. Esta nova concepção nasce, justamente porque foi em razão de que por muito tempo os particulares exercitaram seus direitos se olhar para o bem-estar do próximo que a desigualdade socieconômica marcou (e segue marcando) profundamente a sociedade. A lógica solidarista vem demonstrar que há uma responsabilidade não apenas do Estado, mas também dos particulares, pela busca de uma sociedade efetivamente justa e igualitária. (CARDOSO, 2013)

É da inafastável convivência social ${ }^{12}$ que nasce a regra de conduta de acordo com a qual de um lado não se deve praticar nenhuma espécie de conduta que atente contra a solidariedade social e ao mesmo se deve realizar toda a atividade capaz de desenvolvê-la. Até mesmo a legitimidade da lei estaria atrelada ao respeito a tal princípio. (DUGUIT, 2006) Diga-se ainda que as condutas cooperativas têm origem tão remotas quanto a própria humanidade, isto porque no passado, os grupos que se mostravam mais cooperativos foram justamente os que sobreviveram aos ambientes naturais e sociais hostis, a exemplo de comportamentos percebidos em seres humanos que viveram na África entre 75.000 a 90.000 anos atrás e que se auxiliavam mutuamente na caça de grandes animais. (BOWLES; GINTIS, 2011)

A solidariedade originária da modernidade e realizada mediante assistencialismo e filantropia é percebida enquanto virtude de origem cristã. Esta concepção remonta à solidariedade liberal (conforme valores dispostos no Código Civil Francês de 1804) momento no qual a liberdade individual alcançava seu maior estágio de desenvolvimento. Porém, enquanto a solidariedade é percebida no sentido de caridade ou beneficência, nada se pode exigir juridicamente. A solidariedade que se constrói jurídica e constitucionalmente revela um dever, a exemplo do dever do Estado enquanto provedor dos direitos sociais básicos. (MORAES, 2008) Portanto, perceptível que a lógica solidarista se insere na categoria de uma dever, na medida em que "[...] ao direito de liberdade da pessoa será

\footnotetext{
11 "Art. 3o Constituem objetivos fundamentais da República Federativa do Brasil:

I - construir uma sociedade livre, justa e solidária;

[...]" (BRASIL, 1988)

12 ubi societas, ibi ius
}

Revista do Direito [ISSN 1982-9957]. Santa Cruz do Sul, v. 3, n. 53, p. 104-120, set./dez. 2017. https://online.unisc.br/seer/index.php/direito/index 
contraposto - ou com ele sopesado - o dever de solidariedade social, mas não reputado como um sentimento genérico de fraternidade ou uma ação virtuosa que o indivíduo poderia - ou não - praticar [...]". (MORAES, 2008, p. 245)

Encerrando esta breve digressão a respeito da solidariedade, mencione-se que a ajuda mútua tem raízes profundamente arraigadas na humanidade, razão pela qual o resgate desta postura, em termos jurídicos, parece ser tema de profunda relevância. Conforme menciona Kropotkin (2009, p. 216):

\begin{abstract}
Aí está a essência da psicologia humana. A menos que fiquem enlouquecidos no campo de batalha, os homens "não conseguem" ficar ouvindo apelos de socorro sem responder a eles. O herói vai; e o que o herói faz, todos sentem que deveriam ter feito também. Os sofismas do intelecto não resistem ao sentimento de ajuda mútua, porque este foi nutrido por milhares de anos de vida social humana e centenas de milhares de anos de vida préhumana em sociedade.
\end{abstract}

Percebe-se, assim, que o solidarismo jurídico, nos termos aqui abordados, consolida uma forma de compreender e de exercitar o Direito que foge da mera opção, configurando, isto sim, um dever de conduta individual voltada para o benefício coletivo. Portanto, esta compreensão do Direito deve ser absorvida desde o início da formação jurídica dos operadores do Direito para que seja possível colocar em prática este objetivo fundamental constitucionalmente edificado.

\title{
6. CONSIDERAÇÕES FINAIS
}

É por todas as razões expostas que se compreende que a formação jurídica deve orientar os futuros operadores para que promovam o acesso solidário à justiça: seja prevenindo conflitos, buscando a sua resolução extrajudicial ou pré-processual, e somente em últimos casos recorrendo ao Poder Judiciário. Assim se entende, inclusive, porque a própria política pública de acesso à justiça que vem sendo implementada no Brasil revela disposições que buscam vincular os princípios constitucionais ao exercício cotidiano de solução de litígios. Exemplo disso é o sistema multiportas introduzido pelo Novo Código de Processo Civil e que dá especial atenção aos mecanismo consensuais de enfrentamento de conflitos, dispondo expressamente que o processo civil será orientado conforme as normas constitucionais ${ }^{13}$, e da possibilidade de realização de mediações fora dos limites do Poder Judiciário, ou seja, no âmbito privado ${ }^{14}$.

Portanto, o ensino jurídico deve acompanhar esta lógica no sentido de proporcionar uma formação profissional que se harmonize com a atual concepção de acesso à justiça nos moldes expressos pela Carta Constitucional, ou seja, nos moldes de uma solidariedade jurídica que vincula tanto ao Poder Público quanto aos particulares.

\footnotetext{
13 "Art. 10 O processo civil será ordenado, disciplinado e interpretado conforme os valores e as normas fundamentais estabelecidos na Constituição da República Federativa do Brasil, observando-se as disposições deste Código." (BRASIL, 2015)

${ }^{14}$ A Lei no. 13.140 de 26 de junho de 2015 dispõe sobre o assunto.
} 


\section{REFERÊNCIAS}

ADORNO, Sérgio. Exclusão Socioeconômica e Violência Urbana. In: Sociologias, Porto Alegre, ano 4, no 8, jul/dez 2002, p. 84-135. Disponível em: <http://www.scielo.br/pdf/soc/n8/n8a05>. Acesso em: 15.12.2017.

BENTO, Flávio; MACHADO, Edinilson Donisete. Educação Jurídica e Função Educacional. In: SILVEIRA, V. O.; SANCHES, S. H. D. F. N.; COUTO, M. B. (Organizadores). Educação Jurídica. São Paulo: Saraiva, 2013.

BRASIL. Constituição (1988). Constituição da República Federativa do Brasil. Brasília, DF: Senado Federal, 1988. Disponível em: < http://www.planalto.gov.br/ccivil_03/constituicao/constituicao.htm>. Acesso em: 20.10.2017.

BRASIL, 2009. II Pacto Republicano de Estado por um Sistema de Justiça mais Acessível, Ágil e Efetivo. Disponível em: <http://www.planalto.gov.br/ccivil_03/outros/iipacto.htm>. Acesso em 21.10.2017.

BRASIL, Lei no. 13.105 de 16 de março de 2015. Código de Processo Civil. Disponível em: <http://www.planalto.gov.br/ccivil_03/_ato2015-2018/2015/lei//13105.htm>. Acesso em 20.10.2017.

BRASIL, Lei no. 13.140 de 26 de junho de 2015. Dispõe sobre a mediação entre particulares como meio de solução de controvérsias e sobre a autocomposição de conflitos no âmbito da administração pública. Disponível em: <http://www.planalto.gov.br/ccivil_03/_ato2015-2018/2015/lei/l13105.htm>. Acesso em: 20.10.2017.

BOBBIO, Norberto. Da estrutura à função: novos estudos de teoria do direito. Tradução: Daniela Beccaccia Versiani; revisão técnica de Orlando Seixas Bechara, Renata Nagamine. Barureri, SP: Manole, 2007.

BOWLES, Samuel; GINTIS, Herbert. A cooperative species: human reciprocity and its evolution. New Jersey: Princeton University Press, 2011.

CAPPELLETTI; Mauro; GARTH, Bryant. Acesso à justiça. Tradução: Ellen Gracie Northfleet. S.L. Sérgio Antônio Fabris Editor, 2002.

CARDOSO, Alenilton da Silva. Princípio da Solidariedade: o paradigma ético do direito contemporâneo. São Paulo: Ixtlan, 2013.

. O princípio da solidariedade: a confirmação de um novo paradigma. In: Revista de Direito $\begin{array}{lllllll}\text { Mackenzie, } & \text { v. } & 6, & \text { n. } & 1, & 2012 . & \text { Disponível } \\ \text { em: }\end{array}$ <http://editorarevistas.mackenzie.br/index.php/rmd/article/view/5793/4209>. Acesso em: 20.10.2017.

COUTO, Mônica Bonetti; MEYER-PFLUG, Samantha Ribeiro. A Educação Jurídica no Brasil e os Meios não Contenciosos de Solução de Conflitos. In: SILVEIRA, V. O.; SANCHES, S. H. D. F. N.; COUTO, M. B. (Organizadores). Educação Jurídica. São Paulo: Saraiva, 2013.

CONSELHO NACIONAL DE JUSTIÇA. Justiça em Números 2017: ano base - 2016/ Conselho Nacional de Justiça - Brasília: CNJ, 2017.

DUGUIT, Léon. Fundamentos do direito. Tradução Márcio Pugliesi. São Paulo: Ícone, 2006.

FACCHINI NETO, Eugênio. Reflexões histórico-evolutivas sobre a constitucionalização do direito privado. In:SARLET, Ingo Wolfgang (Organizador). Constituição, direitos fundamentais e direito privado. 3 ed. revista e ampliada. Porto Alegre: Livraria do Advogado Editora, 2010.

GRECO, Leonardo. Instituições de Processo Civil. Volume I. 5 ed. Rio de Janeiro: Forense, 2015. 
KROPOTKIN, Piotr. Ajuda Mútua: um fator de evolução. Tradução: Waldyr Azevedo Jr. São Sebastião: A Senhora Editora, 2009.

LOPES, José Reinaldo de Lima. O Direito na História: lições introdutórias. 3 ed. 3 reimpr. São Paulo: Atlas, 2011.

MATIAS-PEREIRA, José. Manual de Metodologia da Pesquisa Científica, 4ª edição. Atlas, 08/2016. VitalBook file.

MORAES, Maria Celina Bodin de. O Princípio da Solidariedade.In: MATOS, Ana Carla Harmatiuk (Organizadora). A construção ds novos direitos. Porto Alegre: Núria Fabris, 2008.

MORIN, Edgar. A cabeça bem-feita: repensar a reforma, reformar o pensamento. Tradução: Eloá Jacobina. 8 ed. Rio de Janeiro: Bertrand Brasil, 2003.

LAKATOS, Eva Maria; MARCONI, Marina de Andrade. Fundamentos de metodologia científica. 4 ed. ver. e ampl. São Paulo: Atlas, 2001.

PERLINGIERI, Pietro. A Doutrina do Direito Civil na Legalidade Constitucional. TEPEDINO, Gustavo (organizador). In: Direito civil contemporâneo: novos problemas à luz da legalidade constitucional: anais do Congresso Internacional de Direito Civil-Constitucional da Cidade do Rio de Janeiro. São Paulo: Atlas, 2008.

PORTAL MEC. Resolução CNE/CES n 9, de 29 de setembro de 2004. Institui as Diretrizes Curriculares Nacionais do Curso de Graduação em Direito e dá outras providências. Disponível em: <http://portal.mec.gov.br/cne/arquivos/pdf/rces09_04.pdf>. Acesso em: 19.08.2017.

RESCHKE, Ana Paula Goldani Marinotto; BAEZ, Narciso Leandro Xavier. A Eficácia do Direito Fundamental de Aceso à Justiça pela Efetividade do Direito de Razoável Duração do Processo. In: Revista do Direito. Santa Cruz do Sul, v. 1, n. 51, p. 108-124, jan./abr. 2017. Disponível em: <https://online.unisc.br/seer/index.php/direito/article/view/8639/6156> Acesso em: 15.12.2017.

REIS, Jorge Renato dos . A Constitucionalização do Direito Privado e o Novo Código Civil. In: Rogério Gesta Leal. (Org.). Direitos Sociais \& Políticas Públicas: Desafios Contemporâneos. Santa Cruz do Sul: EDUNISC, 2003, v. Tomo 3.

REIS, Jorge Renato dos; FONTANA, Eliane. O Princípio da Solidariedade e a hermenêutica filosófica na sustentabilidade dos Direitos Fundamentais sociais, diante dos argumentos do mínimo existencial e da reserva do possível. In: LEAL, Rogério Gesta; REIS, Jorge Renato dos. (Orgs.). Direitos sociais epolíticas públicas: desafios contemporâneos. Santa Cruz do Sul: Edunisc, 2010.

RODRIGUES, Francisco Luciano Lima. O Fenômeno da Constitucionalização do Direito: seus efeitos sobre o direito civil. In: Direito Civil Constitucional: a ressignificação da função dos institutos fundamentais do direito civil contemporâneo e suas consequências. RUZYK, C. E. P.; SOUZA, E. N.; MENEZES, J. B.; JUNIOR, M. E. (Organizadores). Florianópolis: Conceito Editorial, 2014.

RODRIGUES, Horácio Wanderlei. Acesso à Justiça: concepção e problemas fundamentais. In: RODRIGUES, Horácio Wanderlei. (Org.). O Direito no III Milênio. Canoas: ULBRA, 2000. Conforme explica o autor: Este artigo é, em realidade, um recorte do texto do primeiro capítulo do livro "Acesso à justiça no direito processual brasileiro", publicado por este autor em 1994, através da Editora Acadêmica. Texto disponibilizado no blog do autor para download.

Ensino Jurídico e Direito Alternativo. São Paulo: Editora Acadêmica, 1993.

Acesso à justiça no Estado Contemporâneo: concepção e principais entraves. In: SALES, Lília Maia de Morais; LIMA, Martonio Mont'Alverne Barreto. (Org.). Constituição, Democracia, Poder Judiciário e Desenvolvimento - Estudos em homenagem a José de Albuquerque Rocha. Florianópolis: Conceito, 2008. Este trabalho teve uma primeira versão escrita para o livro Acesso à Justiça no Direito Processual Brasileiro (São Paulo: Acadêmica, 1994). Passados 10 anos, foi agora totalmente reescrito com a ajuda de Danielle Annoni. 
SARMENTO, Daniel. Ubiqüidade constitucional: os dois lados da moeda. In: SOUZA NETO, Cláudio Pereira de; SARMENTO, Daniel. (Coordenadores). A constitucionalização do direito: fundamentos teóricos e aplicações específicas. Rio de Janeiro: Lumen Juris, 2007.

SCHMIDT, João Pedro. ORIENTAÇÃO ATIVA NAS POLÍTICAS PÚBLICAS: DIRETRIZES PARA A TRANSFORMAÇÃO SOCIAL. 2016. No prelo.

SEN, Amartya. A ideia de justiça. Tradução de Denise Bottmann e Ricardo Doninelli Mendes. São Paulo: Companhia das Letras, 2011.

WATANABE, Kazuo. Política Pública do Poder Judiciário Nacional para Tratamento Adequado dos Conflitos de Interesses. Disponível em: <http://www.tjsp.jus.br/Download/Conciliacao/Nucleo/ParecerDesKazuoWatanabe.pdf>. Acesso em: 21.10.2017.

\section{COMO CITAR ESSE DOCUMENTO:}

ZIEMANN, Aneline dos Santos. A superação da dicotomia público versus privado e a concepção solidarista de acesso à justiça no ensino do direito. Revista do Direito, Santa Cruz do Sul, v. 3, n. 53, dez. $2017 . \quad$ ISSN 1982-9957. Disponível em: <https://online.unisc.br/seer/index.php/direito/article/view/11369>. Acesso em: 29 dez. 2017. doi:http://dx.doi.org/10.17058/rdunisc.v3i53.11369. 